\title{
ANALISIS SISTEM INFORMASI GEOGRAFIS (SIG) DALAM PENENTUAN JALUR EVAKUASI, TEMPAT EVAKUASI SEMENTARA (TES) BESERTA KAPASITASNYA DI KOTA PARIAMAN
}

\author{
Dini Purbani1), Ardiansyah²), Harris, M.P.3), Hadiwijaya Lesmana Salim¹), Muhammad Ramdhan'1), \\ Yulius ${ }^{1)}$, Joko Prihantono1) \& Lestari Cendikia Dewi" ${ }^{1)}$ \\ 1)Pusat Penelitian dan Pengembangan Sumber Daya Laut dan Pesisir, Balitbang-KP, KKP \\ ${ }^{2)}$ Asisten Dosen Jurusan Geografi FMIPA, Universitas Indonesia \\ ${ }^{3}$ Badan Pengkajian dan Penerapan Teknologi
}

Diterima tanggal: 22 Januari 2015; Diterima setelah perbaikan: 29 April 2015; Disetujui terbit tanggal 8 Juni 2015

\begin{abstract}
ABSTRAK
Kota Pariaman Tahun 2009 mengalami gempabumi dua kali dengan kekuatan gempa 7,9 SR dan 6,2 SR (USGS, 2009). Dampak yang ditimbulkan terjadi korban jiwa meninggal 46 jiwa, luka berat 64 jiwa dan luka ringan 363 jiwa (BPK - RI 2010) Upaya yang dilakukan untuk meminimalisasi korban jiwa, pemerintah daerah membuat rute evakuasi menuju Tempat Evakuasi Sementara (TES) di lokasi yang aman. Lokasi penelitian berada di Desa Naras Satu, Desa Ampalu, Desa Kampung Baru, Desa Karan Aur, Desa Taluak, Desa Marabau dan Desa Pasir Sunur. Upaya yang dilakukan agar meminimalisasi korban bencana dengan mengevakuasi warga menuju TES dengan jarak tempuh $270 \mathrm{~m}$ yang dapat dicapai dalam waktu 6 menit. Proses analisis SIG menggunakan jaringan jalan (network analysis). Parameter yang digunakan adalah jaringan jalan dan sebaran rumah penduduk. Dari hasil analisis SIG dapat diketahui usulan TES berjumlah 39 unit yaitu 8 unit di Desa Naras Satu, 5 unit di Desa Ampalu, 11 unit di Desa Kampung Baru, 7 unit di Desa Karan Aur, 1 unit di Desa Taluak, 4 unit di Desa Marabau dan 3 unit di Desa Pasir Sunur. Kelayakan TES yang dapat menampung warga antara lain Kantor lama Walikota Pariaman Karan Aur, Mesjid Pasir Sunur, SDN 5 Marabau, SMPN2 Kampung Baru dan SDN 15 Ampalu.
\end{abstract}

Kata kunci: analisis SIG, mitigasi bencana, TES, Kota Pariaman.

\begin{abstract}
Pariaman City experienced two earthquakes in 2009 with magnitudes of 7.9 SR and 6.2SR respectively (USGS, 2014). The impacts to people included 46 died, 64 seriously injured and 36 of slightly injured (BPK - RI 2010). There for, to minimize the death casualties, the local goverment maps evacuation routes to the safeshelters/TES, which located in 7 villages namelyVillages of Naras Satu, Ampalu, Kampung Baru, Karan Aur, Taluak, Marabau and Pasir Sunur. It is designed that the evacuation to the TES of $270 \mathrm{~m}$ distance can be reached within 6 minutes. Hence, a GIS analysis bynetwork analysis is applied. The parameters used are the road network and distribution of houses. So, from the results of GIS analysis it can be seen the number of proposed TES is 39 units, there are : Naras Satu village (8 units), Ampalu village (5 units), Kampung Baru village (11 units), Karan Aur village (7 units), Taluak Village (1 unit), Marabau Village (4 units) and Pasir Sunurvillage (3 units). The TES can accommodate residents arelike, the Office of provost Pariaman at Karan Aur Village, Pasir Sunur Mosque, Public Elementary School (SDN 5) Marabau, Junior High School (SMPN2) Kampung Baru and Public Elementary School (SDN 15) Ampalu.
\end{abstract}

Keywords: GIS analysis, disaster mitigation, TES, Pariaman City.

\section{PENDAHULUAN}

Kota Pariaman dilanda gempabumi Tahun 2009 dengan Magnitudo (Mw) 7,9 dan 6,2 (USGS, 2009). Dampak yang terjadi mengakibatkan korban jiwa meninggal 46 jiwa, luka berat 64 jiwa dan luka ringan 363 jiwa (Satkorlak 2009). Beberapa gempa yang dirasakan sampai ke Kota Pariaman antara lain gempa bumi di Aceh Tahun 2004 berkekuatan 9,2 SR, di Sumatera 2005 kekuatan 8,7 SR, di Bengkulu Tahun 2007 berkekuatan 7,9 SR dan gempa bumi di Sumatera 2012 dengan kekuatan 8,9 SR (Natawidjaja, 2007).

Potensi bahaya (hazard) gempa bumi di Kota Pariaman cukup tinggi karena letaknya yang dekat dengan jalur patahan Semangko (Semangko Fault) atau patahan Barat Sumatera dan juga zona penujaman Lempeng India-Australia di bawah Lempeng Eurasia yang dapat memicu terjadi gempa bumi. Daerah penunjaman lempeng yang berada di dasar laut dapat berperan sebagai megathrust atau sesar anjak naik yang berpotensi untuk membangkitkan tsunami ketika terjadi gempa besar yang diikuti oleh deformasi vertikal di lokasi tersebut.

Wilayah Padang dan sekitar pantai Barat Sumatera merupakan dataran rendah yang memiliki resiko yang besar di dunia dari ancaman tsunami, yang dapat disebabkan oleh gempa bumi yang berasal dari Palung Sunda, karena di wilayah tersebut terdapat seismic gap yang dapat menjadi sumber gempa di masa yang akan datang (Sieh, 2009).

Gempa bumi yang terjadi di Kota Pariaman dapat berasal dari zona penujaman dan Patahan Besar 
Sumatera. Gempa yang berasal dari zona penujaman/ subduksi akibat dari tumbukan dua lempeng yaitu lempeng (Samudra) Hindia atau lempeng IndiaAustralia bergerak menunjam ke bawah lempeng (benua) Sumatra dan busur kepulauan di bagian baratnya adalah bagian dari lempeng Eurasia (Natawidjaja, 2007).

Usaha mitigasi bencana di Kota Pariaman sangat diperlukan mengingat Kota Pariaman merupakan daerah pesisir di Sumatera Barat yang dekat dengan lokasi sumber gempa dan tsunami. Mitigasi tersebut dapat diwujudkan dengan membuat Tempat Evakuasi Sementara (TES) di daerah pesisir yang dapat dijangkau dengan cepat oleh masyarakat saat akan terjadi tsunami (UU 24/2007, UU 27/2007, Perda Kota Pariaman No. 3/2010). Lokasi TES secara umum dapat berupa daerah alami dataran tinggi, daerah tanah tinggi buatan dan struktur baru yang dirancang tahan gempa dan tsunami (FEMA, 2008).

Aplikasi penentuan TES menggunakan teknologi Informasi Geografis. Teknologi informasi Geografis dapat mengelola tentang populasi, infrastruktur dan data distribusi spasial. Misalnya, kemampuan untuk memberikan jawaban atas pertanyaan-pertanyaan penting, seperti dimana daerah yang paling terkena dampak dan bagaimana mencapainya dalam situasi darurat, dapat diatasi dengan menggunakan teknologi SIG (Goodchild, 2006). Pengetahuan IImu Geografi digunakan dalam pengelolaan bencana untuk memandu dan memantau penggunaan lahan, menggambarkan rute transportasi untuk evakuasi yang efektif, dan menggambarkan kembali zona bahaya berdasarkan pengetahuan baru atau perubahan dalam sistem yang alami atau buatan manusia (Greene, 2002).

Purbani et. al. (2014) mengusulkan 23 unit TES dari 12 unit TES yang sudah ada dan jalur horisontal menuju TEA sebanyak 15 jalur di Kota Pariaman.
Wilayah desa pesisir kota ini telah memiliki TES yang bersifat multiguna seperti, Desa Kampung Baru menggunakan lantai 3 SMPN 2 Kampung Baru untuk TES, sementara lantai 1 dan 2 untuk aktivitas belajar. Desa Karan Aur terdapat kantor lama Walikota Pariaman yang dapat dimanfaatkan untuk TES berada di lantai 3. Desa Pasir Sunur memanfaatkan Mesjid Pasir Sunur sebagai TES. Desa-desa di wilayah pesisir hanya sebagian kecil yang mempunyai TES sehingga perlu dilakukan penelitian penentuan lokasi TES.

Perencanaan pembangunan TES perlu memperhatikan nilai percepatan tanah puncak (Peak Ground Acceleration) (Prihantono et al, 2013) dan spektrum respon gempa di lokasi TES Kota Pariaman (Dewi et al, 2014). Berdasarkan hasil penelitian Prihantono et al (2013) nilai percepatan tanah puncak Kota Pariaman berkisar antara $0,35 g-4 g$ yang berarti berada di daerah yang cukup rawan.

Penelitian ini merupakan penelitian lanjutan Tahun 2012. Hasil penelitian tersebut telah dipublikasi di Jurnal Segara dalam Volume 10 edisi Bulan Agustus 2014 dengan judul "Penentuan Tempat Evakuasi Sementara (TES) dan Tempat Evakuasi Akhir (TEA) untuk Gempa Bumi dan Tsunami dengan Pendekatan Sistem Informasi Geografis, Kota Pariaman Provinsi Sumatera Barat". Adapun tujuan dari penelitian adalah: mengetahui lokasi dan daya tampung ideal Tempat Evakuasi Sementara di kota Pariaman melalui analisis jaringan (network analysis) dari data spasial yang diolah menggunakan perangkat sistem informasi geografis.

\section{METODE PENELITIAN}

Penelitian dilakukan di Kota Pariaman pada 31 Maret sampai 16 Juli 2014. Lokasi penelitian berada di Desa Naras Satu, Desa Ampalu, Desa Kampung Baru, Desa Karan Aur, Desa Taluak, Desa Marabau dan Desa Pasir Sunur (Gambar 1).

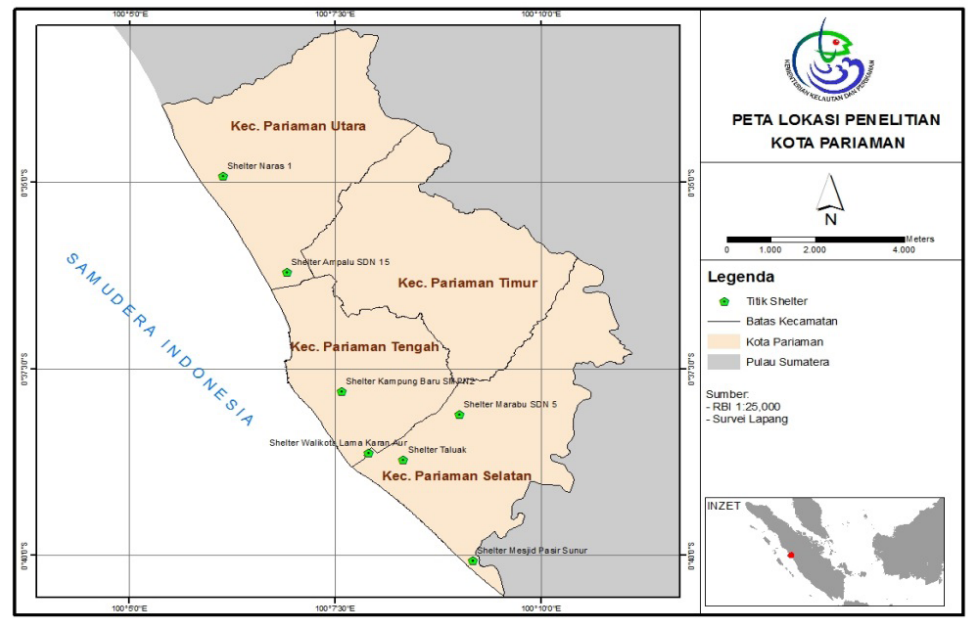

Gambar 1. Lokasi Penelitian. 
Secara geografi, lokasi penelitian berada pada posisi $0^{\circ} 33^{\prime} 00^{\prime \prime}-0^{\circ} 40^{\prime} 43^{\prime \prime}$ LS hingga $100^{\circ} 04^{\prime} 46^{\prime \prime}$ $100^{\circ} 10^{\prime} 55^{\prime \prime}$ BT. wilayah administrasi Kota Pariaman bagian utara berbatasan dengan Kecamatan $\mathrm{V}$ Koto Kampung Dalam (Kab. Padang Pariaman), bagian selatan berbatasan dengan Kecamatan Nan Sabaris (Kab. Padang Pariaman), bagian Timur berbatasan dengan Kecamatan VII Koto Sungai Sariak (Kab. Padang Pariaman) dan bagian barat berbatasan dengan Selat Mentawai.

Data yang dikumpulkan dalam penelitian ini meliputi data primer dan data sekunder. Data primer dikumpulkan di lokasi yang terkena gempa bumi dan tsunami (Tabel 1).

Data Sekunder terdiri dari beberapa peta dan citra. Peta Topografi Kota Pariaman lembar 0715-33 Pariaman skala 1:25.000 yang dikeluarkan oleh Bakosurtanal 1976 digunakan untuk mengetahui lokasi di Kota Pariaman yang rentan. Citra Ikonos Tahun 2006 dan 2009 diperoleh dari Google Earth digunakan untuk mengetahui kondisi Kota Pariaman secara keseluruhan. Data kependudukan diperoleh dari Dinas Kependudukan Kota Pariaman 2014 untuk mengetahui jumlah penduduk di wilayah yang rentan, sehingga dapat diketahui kapasitas TES yang dibutuhkan. Peta zonasi rawan tsunami yang dikeluarkan oleh Pusat Vulkanologi dan Mitigasi Bencana Geologi-Badan Geologi Kementerian Energi Sumberdaya Mineral Tahun 2009 diperlukan untuk mengetahui sebaran luasan genangan tsunami. Peta Penggunaan Lahan dan Peta Jaringan Jalan Kota Pariaman yang dikeluarkan oleh BAPPEDA Kota Pariaman Tahun 2012, digunakan untuk mengetahui kondisi tutupan lahan saat ini.

Langkah awal penentuan lokasi TES adalah mengidentifikasi sebaran permukiman Kota Pariaman dari citra Ikonos sebelum ke lapangan. Unsur sebaran permukiman digunakan untuk mengetahui permukiman yang rentan terhadap tsunami. Langkah selanjutnya adalah verifikasi hasil interpretasi dengan melaksanakan uji lapangan (ground truth). Hasil verifikasi digunakan untuk pembaharuan data permukiman. Pembaharuan data jalan dilakukan berdasarkan Peta Jaringan Jalan dan pemetaanTES yang eksisting.
Atribut yang diperlukan dalam pengelolaan SIG adalah unsur titik, garis dan polygon (Laurini, \& Thompson, 1996). Unsur titik sebagai kota, unsur garis sebagai jalan dan unsur polygon sebagai wilayah permukiman dan zona rawan gempa dan tsunami. Pengolahan atribut SIG menggunakan perangkat lunak Arc View yang memiliki ekstensi network analysis dapat berfungsi untuk menentukan wilayah jangkauan (service area) suatu titik dari jarak yang ditentukan menurut ketersediaan jaringan jalan/aksesibiltas. Dalam penelitian ini, fungsi network analysis digunakan untuk menentukan permukiman yang terjangkau atau tidak terjangkau oleh TES yang telah ada (existing). Setelah itu, fungsi ekstensi ini juga digunakan untuk menentukan lokasi TES usulan yang strategis untuk permukiman yang tidak terjangkau oleh TES yang eksisting. Data jaringan jalan sangat diperlukan dalam proses analisis SIG (network analysis) untuk mengetahui arah evakuasi menuju ke tempat yang lebih aman. Adapun alur kerja tertera pada Gambar 2.

Waktu tiba tsunami lokal yang sangat singkat, antara $10-60$ menit, membuat penyebaran informasi peringatan dini tsunami menjadi sulit. Hal ini akan berdampak langsung pada prosedur evakuasi dan waktu evakuasi yang sangat singkat. Ketika gempa bumi terjadi seluruh sensor pencatat gempa bumi yang berada di stasiun seismik di sekitar sumber gempa bumi akan mencatat data gempa bumi dan mengirimkannya ke pusat pengolahan di BMKG Pusat untuk diproses. Untuk gempa bumi di wilayah Indonesia diperlukan waktu kurang dari 5 menit (TO-T1). (BMKG, 2012). Sistem peringatan dini tsunami di Indonesia lebih dari sekedar teknologi, tetapi juga memerlukan keterlibatan masyarakat di daerah berisiko bencana dan otoritas yang bertugas di semua tingkat dalam mengembangkan kemampuan mereka untuk mengantisipasi terjadinya bencana.

Usaha yang dilakukan dalam mengurangi bencana adalah secepat mungkin mengevakuasi warga menuju tempat yang lebih aman. Oleh karena itu dilakukan usulan TES berupa bangunan vertikal yang mempunyai ketinggian minimum lantai TES adalah elevasi gelombang datang (runup) tsunami maksimum di lokasi TES, ditambah 30\%, ditambah 3 meter, dan dikurangi ketinggian tanah di lokasi TES (FEMA, 2008). Metode untuk penentuan jarak aman

Tabel 1. Jenis data fisik yang digunakan dalam penelitian

\begin{tabular}{llll}
\hline Komponen fisik & $\begin{array}{l}\text { Metode } \\
\text { Pengumpulan Data }\end{array}$ & $\begin{array}{l}\text { Sumber } \\
\text { Data }\end{array}$ & Alat/bahanyang digunakan \\
\hline Penggunaan Lahan & Observasi & In situ & $\begin{array}{l}\text { Meteran, GPS hand held oregon 520, } \\
\text { Daftar Isian, Kamera Digital } \\
\text { Daftar Isian }\end{array}$ \\
Sosial Masyarakat & Wawancara & In situ & Daftian \\
\hline
\end{tabular}




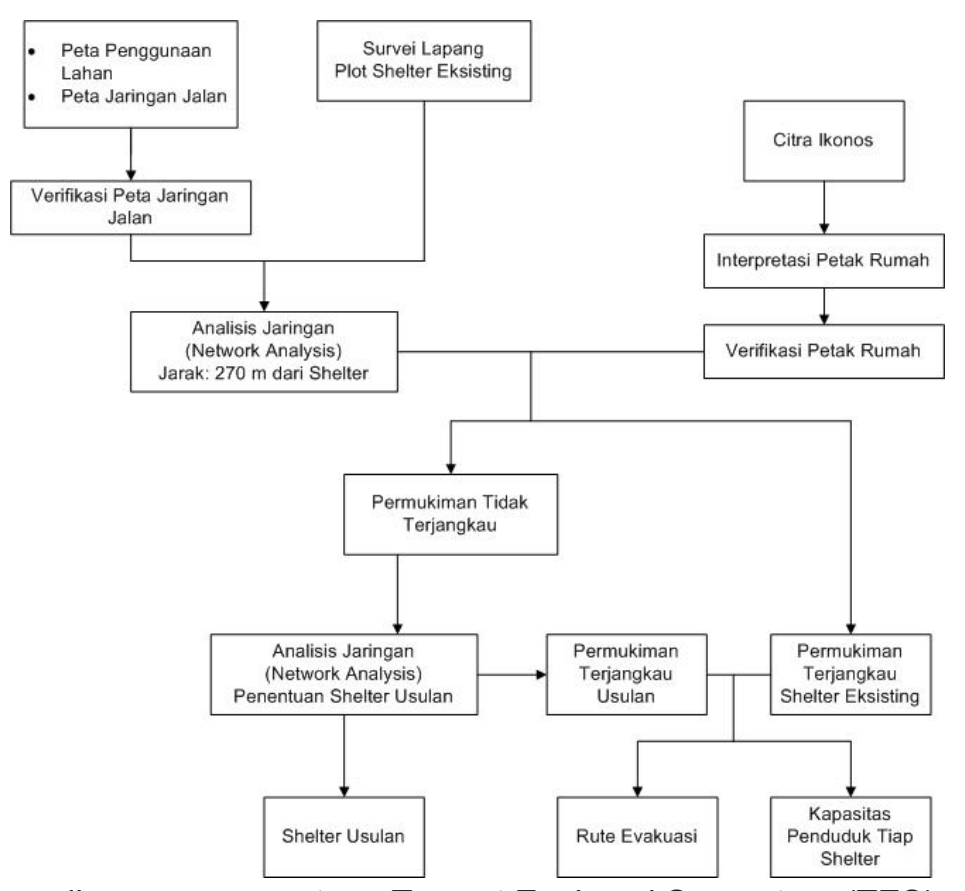

Gambar 2. Diagram alir proses penentuan Tempat Evakuasi Sementara (TES).

untuk mencapaiTES mengacu pada Institute of Fire Safety and Disaster Prepardnes Japan dalam Budiarjo (2006) diterangkan bahwa Kecepatan evakuasi $=0,751$ $\mathrm{m} /$ detik (kecepatan berjalan Manusia Lanjut Usia). Waktu yang digunakan $<10$ menit. Dalam penelitian ini menggunakan waktu 6 menit karena diasumsikan waktu tersebut warga dapat menuju TES yang terdekat. Waktu proses evakuasi $=6$ menit $=6 \times 60$ detik $=360$ detik, Jarak dari TES $=360$ detik $\times 0,751 \mathrm{~m} /$ detik $=$ $270,36 \mathrm{~m}=270 \mathrm{~m}$ (Gambar 3).

Setelah ditentukan jarak tempuh sejauh $270 \mathrm{~m}$ dalam waktu 6 menit maka dilakukan proses network analysis menggunakan jaringan jalan. Dari proses tersebut dapat diketahui TES yang diperlukan di setiap wilayah penelitian (Gambar 3).

Proses penentuan TES ini menggunakan analisis berbasis Sistem Informasi Geografis (SIG). Sistem Informasi Geografis (SIG) merupakan sistem yang terdiri dari komponen (software, hardware, user, dan metode) yang berfungsi untuk menyimpan, mengedit, memanipulasi, dan menganalisis data geografis (Aronoff, 1989). Data dalam SIG selalu terdiri dari 2 komponen, yakni data grafis (line, titik, dan poligon) dan atributnya. Data grafis ini merupakan gambaran yang merepresentasikan ruang atau obyek di muka bumi dan selalu memiliki informasi atribut. Karena kemampuannya dalam mengintergrasikan data grafis (CAD) dan data atribut, SIG telah berkembang hingga dapat mengadopsi 3 jenis teknologi dari beberapa macam software, yakni Relational Database Management System, Computer Assisted Design and Graphics Software, dan Statistical Analysis and

\section{Reporting Packages.}

Software merupakan salah satu kompenen yang terdapat di dalam SIG, yaitu dalam suatu software SIG harus memiliki (Gambar 4):

1. Sistem koordinat, yang mampu membaca data-data yang bereferensi koordinat dan mampu mentransformasikan ke berbagai macam sistem koordinat (geografis maupun proyeksi)

2. Querry, untuk melakukan seleksi dari suatu grafis (titik, garis dan poligon) maupun dari atributnya.

3. Fungsi editing data grafis.

4. Fungsi Pengukuran Geomteris.

5. Sistem Manajemen Basis Data, yang berfungsi untuk menyimpan dan mengelola data spasial.

6. Fungsi Analisis, yang berfungsi untuk menganalisis data spasial

Beberapa software GIS untuk pengolah data vektor maupun data raster antara lain Arc GIS, Map Info, Quantum GIS, ENVI, ERDAS, ER Mapper, PCI, Global Mapper, dll.

Salah satu tools analisis yang digunakan dalam penelitian ini adalah analisis jaringan (Network Analysis). Analisis jaringan merupakan analisis berdasarkan atas jarak yang mengacu kepada jaringan (network). Jaringan yang digunakan dalam analisis jaringan ini adalah data jalan. Selain sebagai prasarana untuk mendukung mobilitas masyarakat, dalam konteks tanggap darurat, jaringan jalan juga digunakan sebagai jalur/akses evakuasi. Jaringan jalan digunakan untuk 


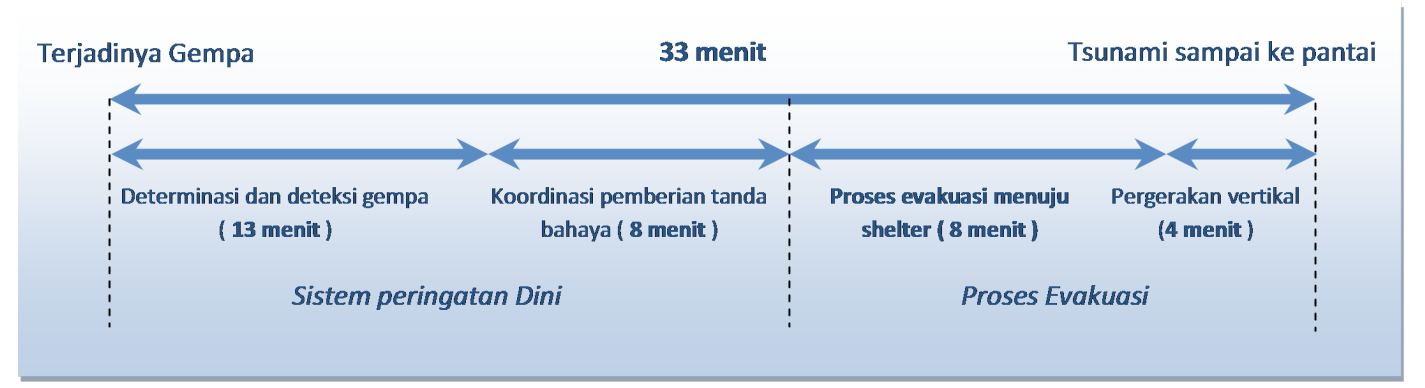

Gambar 3. Waktu terjadinya gempa sampai tsunami tiba di pantai (Sumber: Budiarjo, 2006).

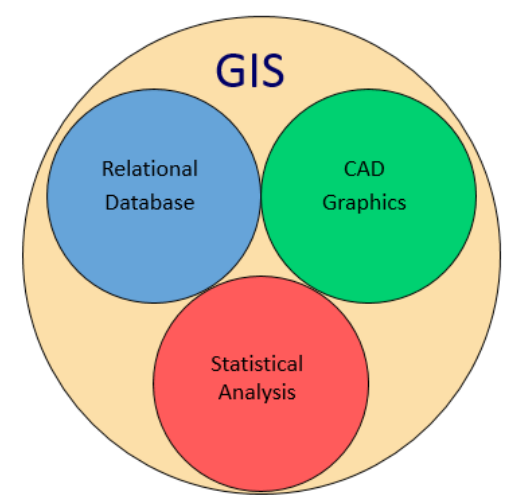

Gambar 4. Hubungan GIS dengan 3 teknologi dari beberapa macam software.

menentukan apakah suatu kelompok masyarakat dapat terjangkau oleh TES yang berjarak maksimum $270 \mathrm{~m}$. Bila terdapat kluster pemukiman masyarakat yang belum terjangkau TES, maka perlu dilakukan penentuan usulan TES.

Proses penentuan jangkauan dari TES yang telah ada (eksisting) yakni dengan menggunakan analisis Service Area yang terdapat pada tools didalam software Arc Gis. Data yang digunakan adalah lokasi TES eksisting dan jaringan jalan dengan penentuan jarak jangkauan sejauh $270 \mathrm{~m}$ dari TES. Hasilnya berupa poligon jangkauan $270 \mathrm{~m}$ dari pusat lokasi TES berada.

Kemudian hasil dari analisis jangkauan sejauh $270 \mathrm{~m}$ tersebut di-overlay dengan data sebaran rumah penduduk. Data sebaran rumah penduduk dihasilkan dari interpretasi citra resolusi tinggi. Hasil overlay tersebut dapat menentukan kluster rumah yang terjangkau TES dan tidak terjangkau TES. Bagi kluster rumah yang tidak terjangkau TES, maka proses selanjutnya adalah penentuan titik usulan TES. Penentuan titik usulan TES ini ditentukan dengan pendekatan: lokasi berada di percabangan jalan, lokasi sebaran usulan TES harus memiliki jangkauan usulan TES yang tidak saling ber-overlap dengan jangkauan TES lainnya dan seluruh titik usulan TES menjangkau seluruh rumah.

Setelah seluruh rumah terjangkau baik TES eksisting maupun TES usulan, selanjutnya adalah proses spatial join antara data sebaran rumah dengan poligon jangkauan TES. Spatial join ini bertujuan agar setiap rumah memiliki ID terhadap tujuan TES-nya masing-masing. Setelah itu, maka akan didapat jumlah rumah yang terjangkau di setiap TES. Dari jumlah rumah yang terjangkau di masing-masing TES tersebut kemudian diestimasi jumlah penduduk yang ditampung dengan pendekatan 1 rumah dihuni oleh 6 orang. Output dari penelitian ini adalah peta jangkauan TES eksisting dan TES usulan sejauh $270 \mathrm{~m}$, jumlah kapasitas TES, serta peta rute jalan menuju TES terdekat.

\section{HASIL DAN PEMBAHASAN}

Resiko dijelaskan sebagai kondisi yang dapat memiliki kemungkinan penyimpangan yang merugikan dari hasil yang diharapkan atau diperkirakan (Vaughan, 1997). Definisi resiko secara matematis merupakan bencana $x$ kerentanan. Sementara bencana didefinisikan sebagai proses atau fenomena yang mungkin, dengan probabilitas tertentu, merupakan peristiwa yang merusak. Dan, "kerentanan" adalah suatu kondisi atau proses yang dihasilkan dari faktorfaktor fisik, sosial, ekonomi dan lingkungan yang menentukan kemungkinan skala kerusakan dari dampak bahaya yang terjadi (Cochard et al, 2008). Manajemen risiko harus fokus pada perlindungan penduduk dari gelombang tsunami dengan pemetaan yang cermat terhadap potensi wilayah yang terpapar 
dan objek penting dalam usaha mitigasi resiko yang tepat (Salap et al., 2011).

Rencana mitigasi untuk pengelolaan bencana meliputi rekonstruksi dan langkah-langkah persiapan untuk kejadian bencana. Karena kita ketahui sumber bencana disebabkan oleh gempabumi, zona-zona yang terkena dampak bencana ditentukan menggunakan SIG. Peta inundasi dibangun dengan SIG digunakan untuk berbagai keperluan. Perpotongan-perpotongan dari gedung dan lembaran-lembaran jalan dan peta lembaran inundasi digunakan untuk mendeteksi gedung yang terkena gelombang tsunami (Salap et al., 2011)

Lokasi penelitian berada di zona rawan gempabumi, tsunami dan berjarak dekat dengan garis pantai. Berdasarkan hasil pengamatan lapangan di wilayah penelitian diketahui; Desa Naras Satu yang berjarak $497 \mathrm{~m}$ dari garis pantai, belum memiliki TES. Menurut Dinas Kependudukan dan Catatan Sipil (DKC), Kota Pariaman, 2014 jumlah penduduknya mencapai 2.435 jiwa. Masyarakat setempat mengusulkan dibuatkan TES di atas lahan bekas rawa seluas 3.000 $\mathrm{m}^{2}$.Desa Ampalu berjarak $515 \mathrm{~m}$ dari garis pantai dengan jumlah penduduk 1.921 (DKC, 2014). TES yang diusulkan berada di SDN15 terdiri dari 2 lantai, yaitu lantai 1 dan 2 untuk aktifitas mengajar, dan rencana TES berada di atas lantai 2. Desa Kampung Baru berjarak $822 \mathrm{~m}$ dari garis pantai, dengan jumlah penduduk 3.576 (DKC, 2014). Desa tersebut sudah memiliki TES di SMPN 2, yaitu lantai 1 dan 2 untuk aktifitas mengajar sedangkan TES berada di lantai 3 berupa area terbuka (dak). Desa Karan Aur berjarak $524 \mathrm{~m}$ dari garis pantai dengan jumlah penduduk
2.303 jiwa (DKC, 2014). Lokasi tersebut sudahmemiliki TES di Kantor Walikota lama Pariaman yang berada di lantai 3 area terbuka (dak). Desa Taluak berjarak 869 $\mathrm{m}$ dari garis pantai. Jumlah penduduknya 3.302 jiwa (DKC, 2014). Desa ini belum memiliki TES. Masyarakat setempat mengusulkan luas lahan seluas 1 ha untuk TES. Desa Marabau berjarak $2.651 \mathrm{~m}$ dari garis pantai. Wilayah ini paling jauh dari garis pantai, berpenduduk 980 jiwa (DKC, 2014). TES yang diusulkan berada di SDN 05 terdiri dari 3 lantai. Lantai 1 dan 2 untuk aktifitas mengajar sedangkan lantai 3 sebagai TES. Desa Pasir Sunur yang berjarak hanya $172 \mathrm{~m}$ dari garis pantai, merupakan wilayah yang paling rentan karena sangat dekat Samudera Hindia dan dibatasi oleh Sungai Batangmangor. Jumlah penduduknya 326 jiwa (DKC,2014). TES yang diusulkan adalah Mesjid Al Mukmin yang berlantai 3, yaitu lantai 1 dan 2 digunakan untuk aktifitas ibadah sedangkan lantai 3 berupa ruang terbuka sebagai TES.

TES yang tersedia di wilayah pesisir hanya berjumlah 3 unit yaitu di Desa Kampung Baru, Desa Karan Aur dan Desa Pasir Sunur. Sebagian besar pesisir belum memiliki TES sehingga dilakukan penentuan TES dengan network analysis. Dari hasil analysis dengan menggunakan parameter permukiman dan jaringan jalan diperoleh sejumlah TES usulan. TES tersebut berada di area yang mudah dijangkau oleh penduduk sejauh 270 m,dari TES usulan.

Berikut adalah hasil olahan SIG dengan menggunakan network analysis (Gambar 5, Gambar 6, Gambar 7, Gambar 8, Gambar 9 dan Gambar 10):

Hasil olahan SIG dapat diketahui jumlah TES

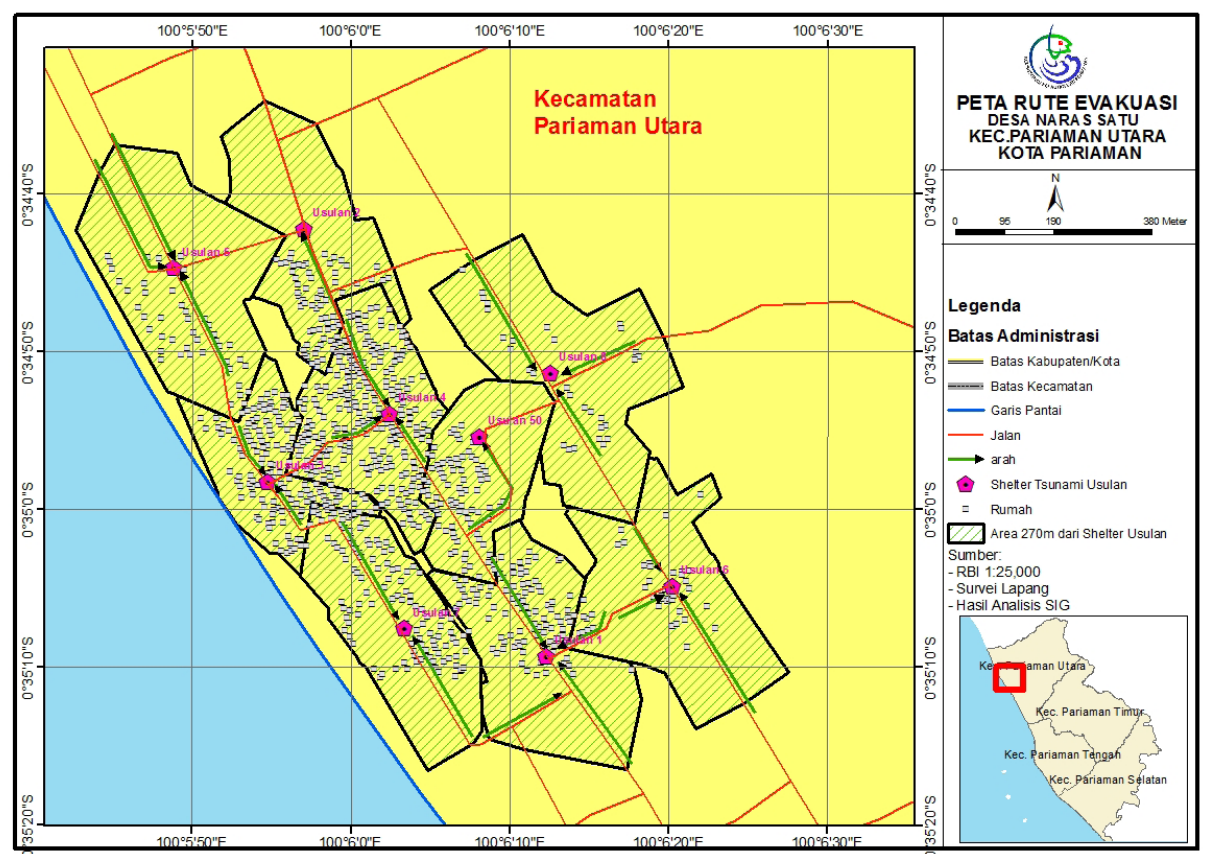

Gambar 5. Lokasi TES usulan dan TES eksisting Desa Naras Satu. 


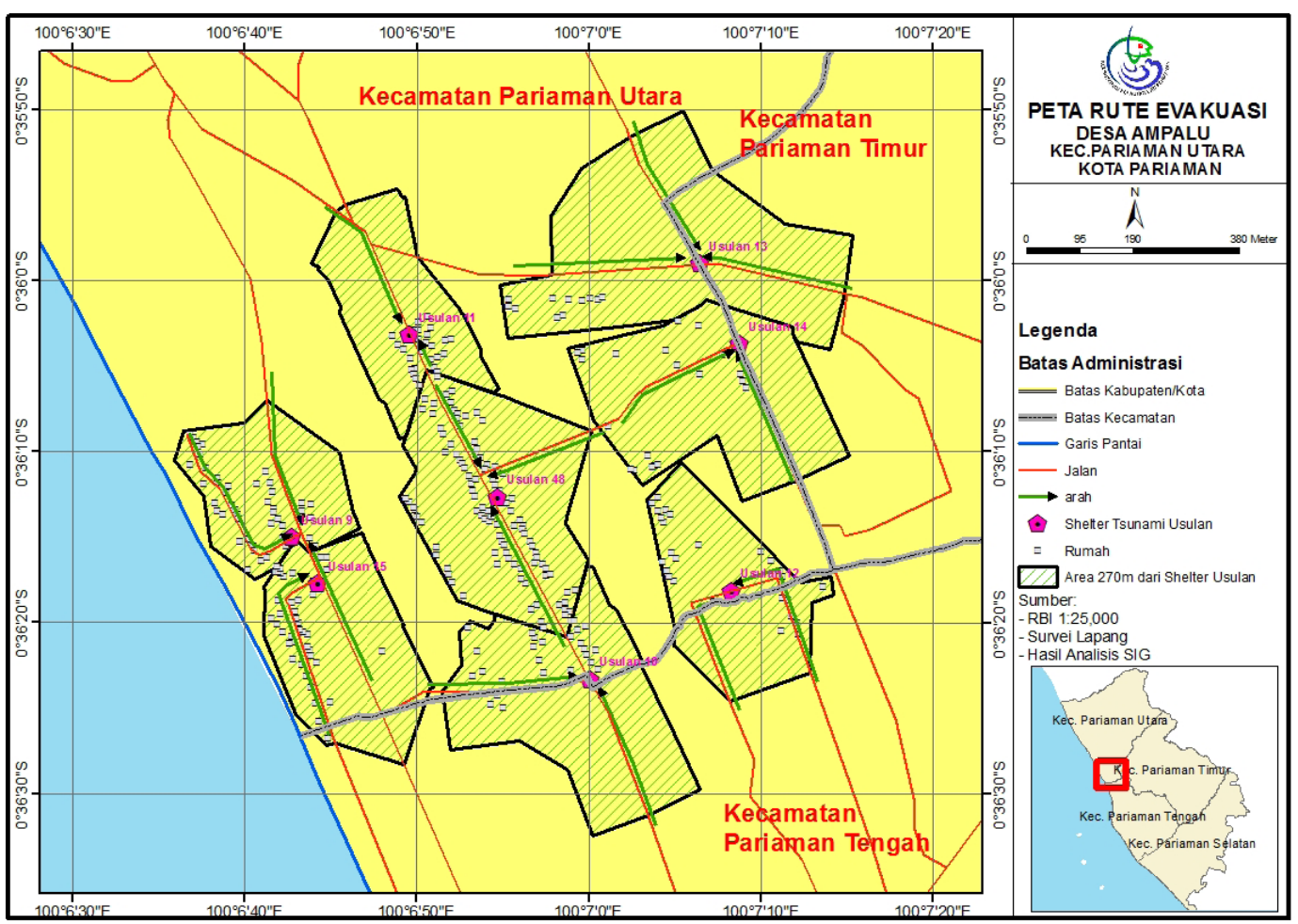

Gambar 6. Lokasi TES usulan dan TES eksisting Desa Ampalu.

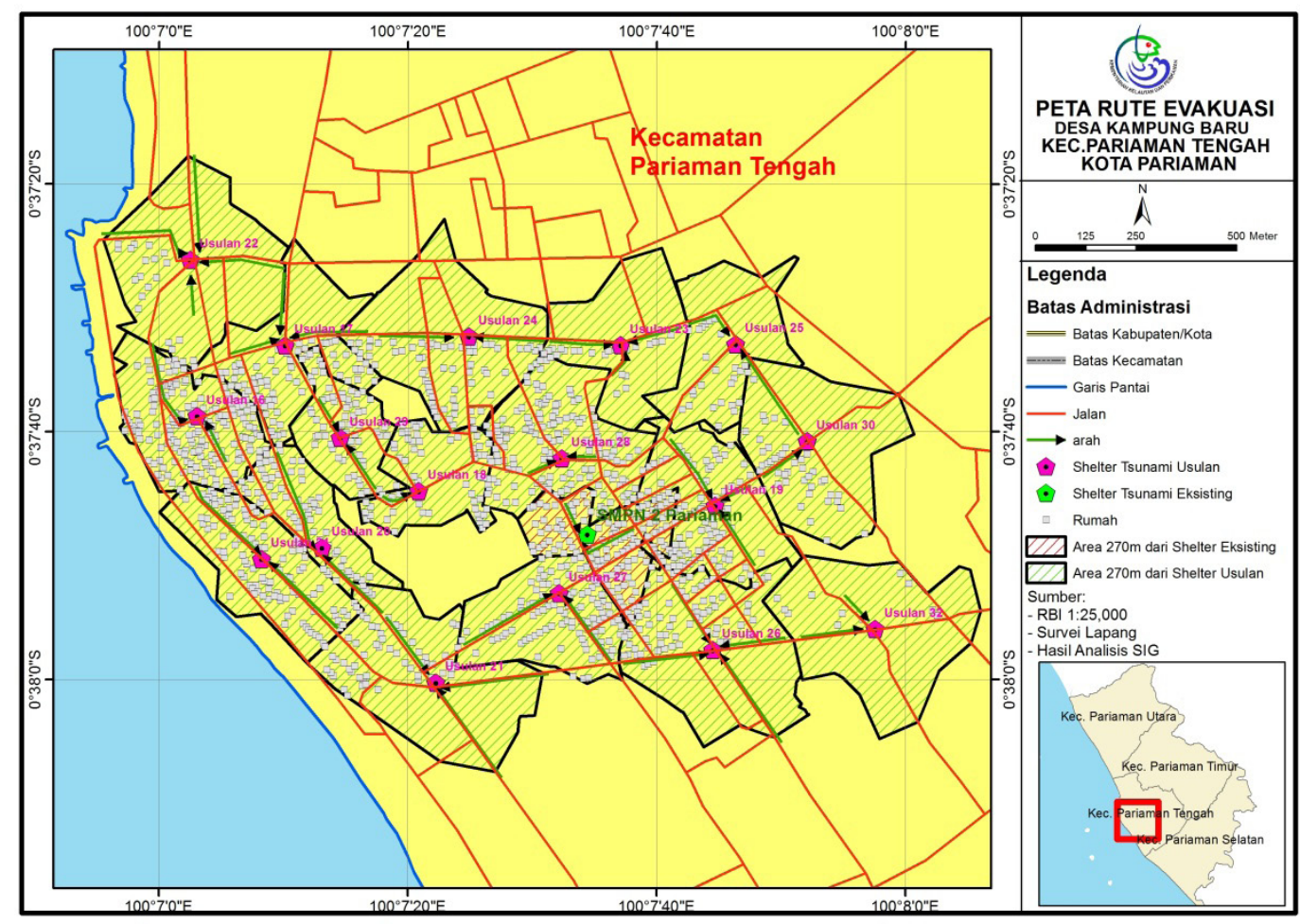

Gambar 7. Lokasi TES usulan dan TES eksisting Desa Kampung Baru. 


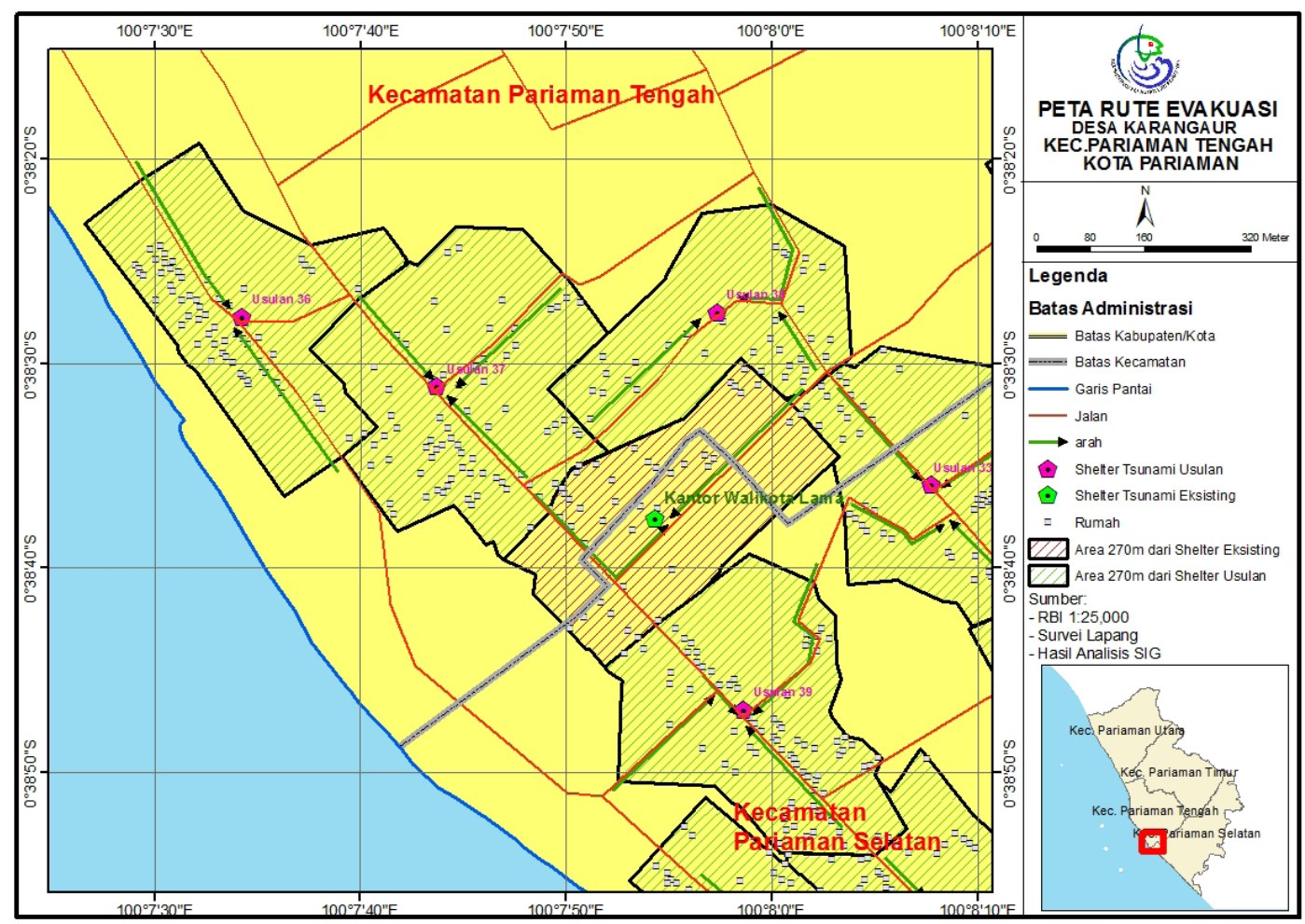

Gambar 8. Lokasi TES usulan dan TES eksisting Desa Karan Aur.

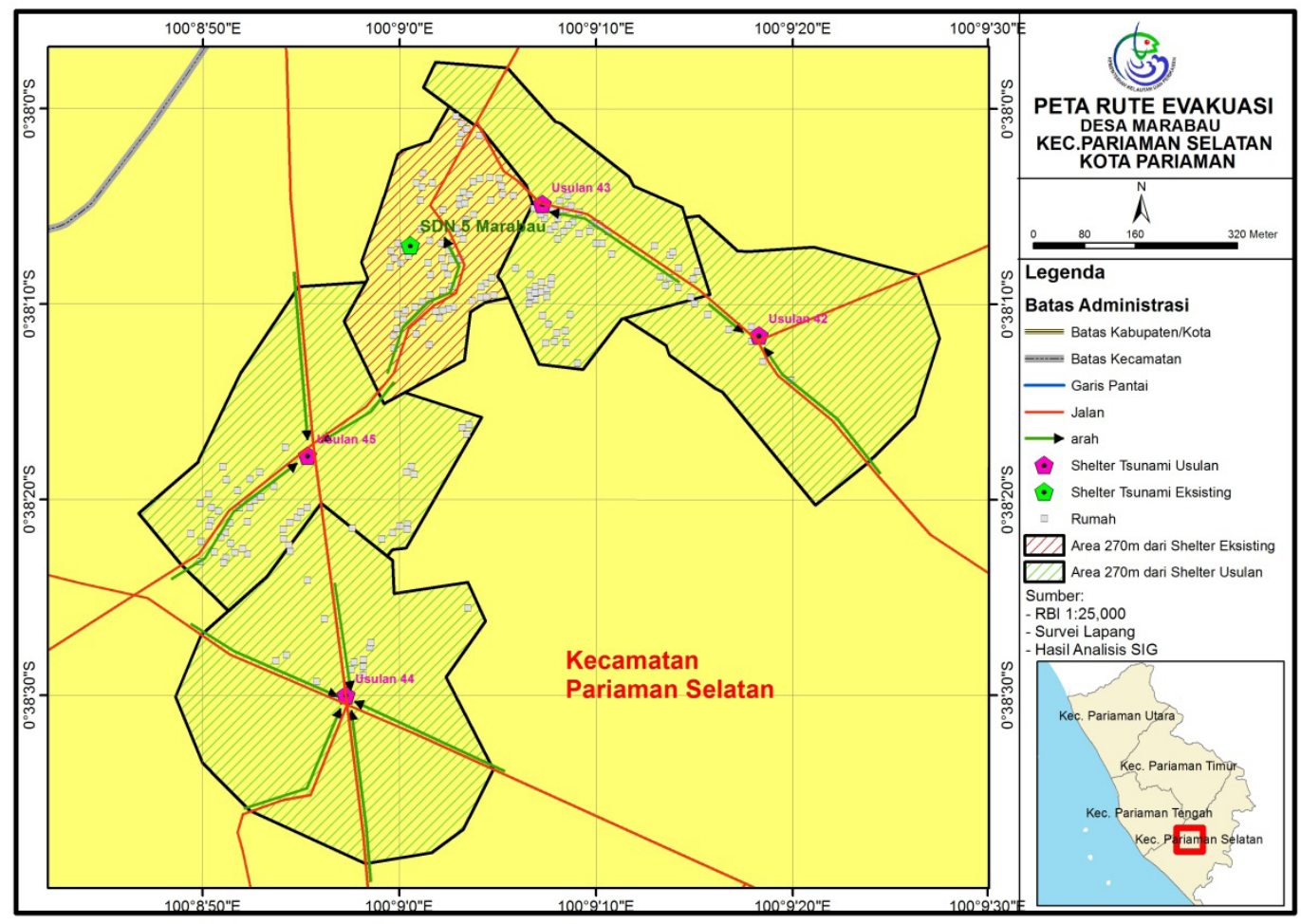

Gambar 9. Lokasi TES usulan dan TES eksisting Desa Marabau.

yang diperlukan di setiap lokasi penelitian. Adapun TES usulan tertera pada Tabel 2.

\section{Kapasitas TES}

Setelah TES usulan diketahui di setiap lokasi penelitian selanjutnya perlu diketahui masing-masing kapasitas TES, agar semua warga terakomodasi mendapatkan tempat evakuasi. Penentuan kapasitas TES mengacu pada FEMA 2008. Kapasitas TES adalah besaran luas bangunan TES, yang luasnya tergantung pada rencana jumlah orang yang akan ditampung 


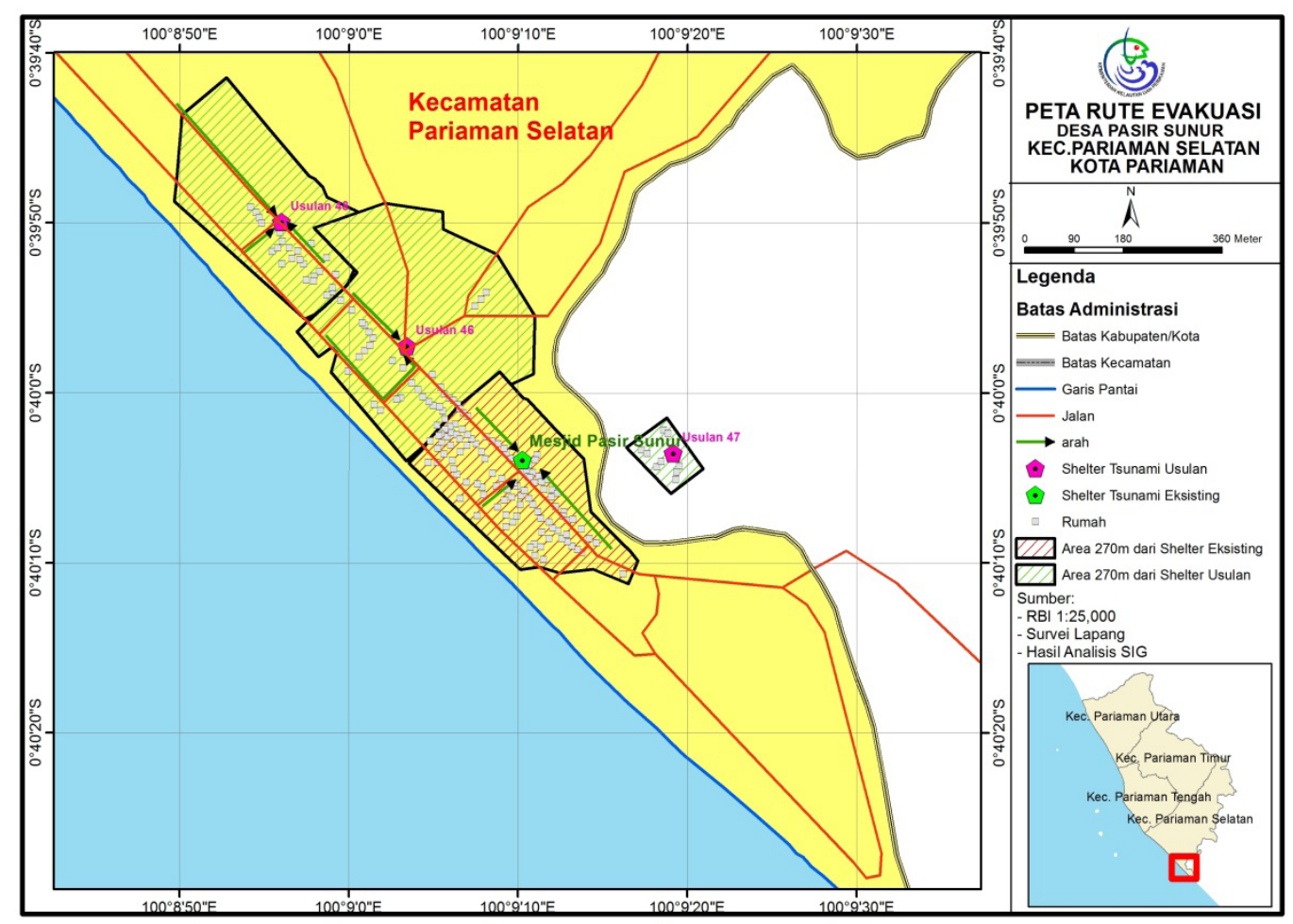

Gambar 10. Lokasi TES usulan dan TES eksisting Desa Pasir Sunur

Tabel 2.

TES usulan di setiap wilayah penelitian

\begin{tabular}{llll}
\hline No & Desa & Eksisting & Usulan \\
\hline 1. & Naras Satu & - & 9 \\
2. & Ampalu & - & 8 \\
3. & Kampung Baru & 1 & 17 \\
4. & Karan Aur & 1 & 6 \\
5. & Taluak & - & 3 \\
6. & Marabau & 1 & 4 \\
7. & Pasir Sunur & 1 & 3 \\
\hline
\end{tabular}

untuk evakuasi di dalam TES. Secara fungsional TES menyediakan tempat evakuasi sementara selama terjadi tsunami atau digunakan juga untuk bencana lain seperti banjir besar. Kapasitas yang sesuai untuk para korban selama beberapa hari di TES adalah $1 \mathrm{~m}^{2}$ untuk 2 orang dengan evakuasi sementara (kurang dari 24 jam) dalam kondisi berdiri atau duduk (ITB, 2013).

\section{KESIMPULAN DAN SARAN}

Penerapan nertwork analysis yang diolah dengan analisis SIG menghasilkan jarak yang diperlukan menuju TES sejauh $270 \mathrm{~m}$ dalam waktu 6 menit. TES usulan di setiap lokasi penelitiaan adalah 9 unit di Desa Naras Satu, 8 unit di Desa Ampalu, 17 unit di Desa Kampung Baru, 6 unit di Desa Karan Aur, 3 unit di Desa Taluak, 4 unit di Desa Marabau dan 3 unit di Desa Pasir Sunur.
Desa Kampung Baru memiliki jumlah penduduk terpadat di Kota Pariaman yaitu 3.576 jiwa. Jarak dari garis pantai $822 \mathrm{~m}$ dan luas daya tampung TES $176 \mathrm{~m}^{2}$. Diperlukan penambahan TES agar dapat menampung seluruh warga.

Desa Pasir Sunur memiliki lokasi dekat dengan garis pantai dan dibatasi oleh Sungai Batangmangor. Desa ini berjarak dari garis pantai $172 \mathrm{~m}$, memiliki jumlah penduduk 326 jiwa dan luas daya tampung TES sebesar $232 \mathrm{~m}^{2}$. Desa Pasir Sunur diprioritaskan untuk penambahan TES.

\section{PERSANTUNAN}

1. Kepala Pusat Penelitian dan Pengembangan Sumberdaya Laut dan Pesisir yang memberikan fasilitas dalam penelitian di Kota Pariaman.

2. Kepala Badan Penanggulan Bencana Daerah 
Kota Pariaman yang memberikan data dan informasi kondisi Kota Pariaman.

\section{DAFTAR PUSTAKA}

Aronoff, S. (1989). Geographic Information System: A Management Perspective. Canada, Ottawa: WDL Publication.

[BMKG] Badan Meteorologi Klimatologi \& Geofisika (2012). Pedoman Pelayanan Peringatan Dini Tsunami

[BPK-RI] Badan Pemeriksa Keuangan Republik Indonesia (2010). Laporan Hasil Pemeriksaan Atas Kegiatan Penanganan Bencana Gempa Bumi Untuk Masa Tanggap Darurat Pada Pemerintah Kota Pariaman Tahun Anggaran 2009 Di Pariaman

Budiarjo, A. (2006). Evacuation Shelter Building Planning for Tsunami- prone Area; a Case Study of Meulaboh City, Indonesia.- Master thesis, International Institute for Geo- information Science and Earth Observation, Enschede 112pp

Dewi, L.C., Joko, P., Dini,P \& Mulyo, H.P. (2014). Respon Spektrum Desain Pada Lokasi Tempat Evakuasi Sementara Tsunami Di Kota Pariaman. Jurnal Segara Vol. 10 No. 2 hal. 165-171 Desember 2014. ISSN 1907-0659.

[DKC] Dinas Kependudukan dan Catatan Sipil Kota Pariaman (2014)

Cochard, R., L. Senaratne., Ranamukhaarachchi., Shivakoti, G.P., Shipin,O.V., Edwards,P.J., Seeland,K.T. (2008). The 2004 tsunami in Aceh and Southern Thailand: A review on coastalecosystems, wave hazards and vulnerability. Perspectives in Plant Ecology, Evolution and Systematics 10 (2008) 3-40

Goodchild, M. (2006). GIS and disasters: Planning for catastrophe. Computers, Environment and Urban Systems Volume 30, pp 227-229

Greene, R. W. (2002). Confronting Catastrophe: A GIS Handbook. Redlands, CA, ESRI Press International Federation of Red Cross and Red Crescent Societies (IFRCRCS) 2002 WorldDisasters Report: Focus on Reducing Risk. Bloomfield, CT, Kumarian Press.

[FEMA] Federal Emergency Management Agency (2008). Guidelines for Design of Structures forVertical Evacuation from Tsunamis, FEMA P646,June.
[ITB] institut Teknologi Bandung, (2013). Pedoman Teknik Perencanaan Tempat Evakuasi Sementara (TES) Tsunami.

Laurini, R. \& Thompson, D. (1996). Fundamentals of spatial information systems. Academic Press, pp 61-108

Natawijadja, D.H. (2007). Gempa bumi dan Tsunami di Sumatra dan Upaya untuk Mengembangkan Lingkungan Hidup yang Aman dari Bencana Alam.

[USGS] United Geological Survey Earthquake. (2009) Magnitude 7,6 Southern Sumatera Indonesia http://earthquake.usgs.gov/earthquakes/ recenteqsww/Quakes/us2009mebz.php/ Maret 2013]

Indonesia, Republik. (2007). Undang-Undang Republik Indonesia Nomor 24 Tahun 2007 Tentang Penanggulangan Bencana.

Indonesia, Republik. (2007). Undang-Undang Republik IndonesiaNomor 27 Tahun 2007 Tentang Pengelolaan wilayah Pesisir dan Pulau-pulau Kecil.

Peraturan Daerah Kota Pariaman, Nomor 3 Tahun 2010 Tentang Penanggulangan Bencana.

Prihantono, J., Guntur, P., Dini, P., Lestari, C, D \& Rikha, B. 2013. Studi Bahaya Guncangan Tanagh Menggunakan Metode Probabilistik Sebagai Upaya Mitigasi Bencana Gempa Bumi di Pesisir Propinsi Sumatera Barat. Jurnal Segara Vol. 9 No. 2 hal. 85-94 Desember 2013. ISSN 1907-0659.

Purbani, D., Ardiansyah, Lestari C,D \& Joko, P. 2014. Penentuan Tempat Evakuasi Sementara (TES) dan Tempat Evakuasi Akhir (TEA) untuk Gempabumi dan Tsunami dengan Pendekatan Sistem Informasi Geografis, Kota Pariaman Propinsi Sumatera Barat. Jurnal Segara Vol. 10. No. 1 hal. 1-12 Agustus 2014. ISSN 1907-0659.

Sieh, Kerry. (2009). Padang Earth quake Struck at Edge of Zone Where Much Bigger Quake is Expected. http://www.earthobservatory.sg/news/ 2009/

Satkorlak. (2009).Recapitulation of West Sumatra EQ Impacts Friday, October 23," circulatedby UN OCHA, Sumatra.

Salap,S., Ayça,A., Akyürek,Z. \& Yalçiner, A, C. (2011). Tsunami Risk Analysis and Disaster Management by Using GIS: A Case Study in Southwest Turkey, 
Analisis Sistem Informasi Geografis (SIG)...di Kota Pariaman (Purbani, D. et al.)

Göcek Bay Area. AGILE 2011, April 18-22

Vaughan, E.J. (1997). Risk Management. Wiley, New York. 